\title{
SOCIALIZATION ON TREATMENT AND PREPARATION FOR VISIT TO DENTIST FOR CHILDREN WITH AUTISM SPECTRUM DISORDERS
}

\author{
Witriana Latifa ${ }^{1 *}$, Ika Anisyah ${ }^{1}$, Rini Triani ${ }^{1}$ \\ ${ }^{1}$ Prof. Dr. Moestopo (Beragama) University \\ *witriana.1@dsn.moestopo.ac.id
}

\begin{abstract}
This community service activity is carried out in the form of activity (socialization) on how to educate and prepare children with Autism Spectrum Disorders (GSA) in brushing teeth and visiting dentists for dental care. This activity was conducted using the methods of lecturing, demonstration, and discussion with parents, caregivers and teachers of children with special needs for autism. This was carried out one day at the Bina Balita nursing home of Social Welfare Office of DKI Jakarta.
\end{abstract}

Keywords: Autism spectrum disorders, brushing teeth, visiting dentists

\section{INTRODUCTION}

Autism Spectrum Disorders (GSA), commonly called autism or autistic, are neurodevelopmental complex disorders that have characteristics of communication disorders, social interaction, repetitive activities and interest limitation (1-3). The term GSA is found more appropriate to describe individuals with autism as GSA does not show a single condition but rather there is a wide variation in their abilities and disabilities. This spectrum may show individuals who are very low functioning, nonverbal, aggressive and antisocial to individuals who are very high functioning, verbal and can start a conversation (4). Autism has been known for 50 years, but the exact cause is still unknown.

Deficits in social skills, among others, will indicate children who do not care about the attention of their parents or others and tend to prefer loneliness. These children rarely make eye contact, use gestures/body language or vocals to attract the attention of others (5). Children with GSA also exhibit atypical behaviors such as unusual behaviors, unnatural attraction with an object, obsessive, compulsive, stereotyped and also have a tendency to self-harm. The ability to play also shows different things; they tend to repeat, lack of creativity and imagination (1). Other characteristics that exist in individuals with GSA show great difficulty in dealing with sudden changes, so that these individuals are said to want something that is always the same/ritualistic and routine (6). But not all children with GSA have speech disorders. Some children do have difficulties in language, but some other with GSA are able to speak, although sometimes it is not functional and without communication purposes. The speech delivered is sometimes echolalia or imitation of what they hear (5).

GSA does not recognize race, social status or education level of parents and generally has started to be detected before the age of three. Boys have the possibility of being individuals with GSA four to five times higher than girls. Girls with GSA tend to show signs of more severe disorders. ${ }^{4}$

The latest data released by the Centre for Disease Control and Prevention (CDC) in America in 2018 , state that there was an increase of $1.5 \%$ from the previous data. Initially, the number of 8 -yearolds with GSA was 1:68 and in 2018 was 1:59. (7) While there was no official data in Indonesia, the speech from the Indonesian Ministry of Health on 2013 World Autism said that the possibility of children under 15 years with GSA is approximately 112 thousand people. This calculation uses the assumption of child prevalence with GSA in Hong Kong (8).

Oral and dental health in GSA children tends to be low due to communication disorders or sensory and motoric impairments which make it difficult to maintain routine dental and oral hygiene. Oral problems with children with GSA are caused by destructive oral habits, such as gingival piercing, lip biting, continuous wetting/licking of the lips, sticking out the tongue or inserting foreign objects into the mouth (pica) as well as medicine to deal with behaviors (9-11). 
Some researchers revealed that there were no significant differences in oral hygiene status, dental restoration treatment needs and gingivitis problems in children with GSA compared to children with typical development. (3) However, a research conducted by Kopycka suggested that parents of children with GSA tend to say that their child has dental problems. The most common dental problems are cavities, irregular dental structures, poor oral hygiene and bruxism (12).

Dental care in children with GSA in a dental clinic often creates problems that make treatment difficult. This is often caused by a behavior disorder by children with GSA as well as limited communication problems or inappropriate sensory responses. Behavioral disorders can be triggered by anxiety due to audio and visual stimuli from dental equipment (13).

Some children with GSA have better visual understanding than audio. Many visual studies have been developed to facilitate communication with children with GSA. An image or visual approach is considered an effective medium for children with GSA to communicate (14-16).

One study produced pictures to prepare children for dental visit. These pictures are arranged to make it easier for dentists to prepare children for dental procedures as well as for parents to prepare children for dental visits (17).

In a community service activity for the community of parents who have children with GSA, socialization is carried out on the pictures. Parents are introduced to these pictures so they can train and prepare their children to be more ready to visit the dentist.

This community service activity is organized by the 'Masyarakat Peduli Autisme' (Mpati) foundation which is a non-profit organization that aims to provide education and training to parents/families that have children or family members with GSA especially disadvantaged families.

\section{METHOD}

This community service activity is organized by Mpati foundation by taking place at Bina Balita Nursing Home of Social Welfare Office of DKI Jakarta Pondok Bambu, Ciapus, East Jakarta. Though inviting parents of children with GSA from disadvantaged families, this activity was also attended by parents of children with other GSA.

This activity raised the topic "Teaching children to brush their teeth and prepare them for dental visits". This activity was carried out by a lecture, demonstration and discussion. The lecture was given by a keynote speaker with a visual presentation method that displayed several slides. The slides explained how to brush child's teeth and pictures related to dental care in the dental clinic.

Meanwhile, the demonstration was carried out in conjunction with the slide show related to things that were demonstrated. It was done with several aids such as jaw models, toothbrushes, flashlights, gargle glasses and some standard dental check tools such as mouthpieces, tweezers and explorer. While the discussion was carried out after the lecture and demonstration were completed, that is by giving the audience the opportunity to ask questions. After the training education in this community service activity was completed, an evaluation was conducted with Mpati foundation.

\section{RESULTS AND DISCUSSION}

This community service activity was attended by 26 parents and teachers of children with GSA. This activity was opened by the Head of Mpati Foundation Program, followed by the keynote speaker that is the main author of this community service report. The event took place from $09.00-11.30$ WIB. The event was also attended by one representative from Bina Balita Nursing Home of Social Welfare Office of DKI Jakarta.

The discussion session was in great demand by the participants, which was concluded from the many questions raised that were full of enthusiasm from parents and teachers. This session developed into sharing experiences between the keynote speaker, parents and teachers. Questions raised by participants would be answered by the keynote speaker, but the speaker then invited other participants who had similar cases to express their experiences.

Questions asked by participants about how to care for children's teeth can be divided into: (1) how to brush teeth efficiently. This question includes the shape or type of ideal toothbrush for ABK, the technique of brushing teeth in $\mathrm{ABK}$ and training to reduce the reflex of vomiting in children every 
time they brush their teeth. The next question can be grouped in (2) what the precautionary measures against cavities are, and (3) what about children who swallow toothpaste because they cannot gargle.

The next question is about preparing children for dental visits. The questions asked by the participants were not as many questions as about how to care for teeth. The question arose after the explanation from the keynote speaker that triggered more curiosity on technically preparing the child.

Questions about the types and shapes of toothbrushes and tooth brushing techniques were answered by the keynote speaker not different from those of children in general. All types and shapes of toothbrushes that are widely available on the market can be used. The emphasis was more on the frequency and adequate brushing techniques and not on the type or shape of the toothbrush. The choice of type of toothbrush for adults and children was welcome at the comfort of parents and children. However, it is recommended that children with primary teeth use a toothbrush with a small brush head so that it is not difficult to reach the back tooth area due to small mouth opening.

In older children, they need to be trained to brush their teeth by themselves by standing in front of the mirror and displaying some pictures showing tooth brushing techniques. This teaching requires continuous patience and repetition. Some ABK including children with GSA often have difficulty holding the handle of a small toothbrush. Several ways are taken to modify this small handle, among others by installing a rubber handrail on a bicycle or a roll of towel. This addition of rubber or towel causes the diameter of the toothbrush handle to be more easily held (figure 1) (18).
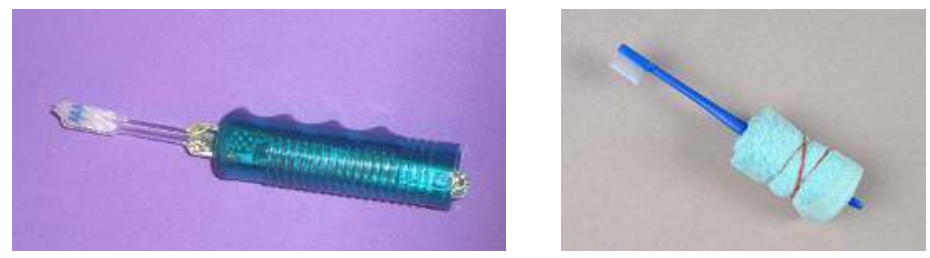

Figure 1. Modification of toothbrush handle

In addition to manual toothbrushes, electric toothbrushes can also be provided. Some children with GSA can clean their teeth better using this type of toothbrush. Not long ago a three-sided toothbrush was launched which could make it easier for ABK including children with GSA to brush their teeth. This toothbrush offers one movement that can cover three tooth surfaces. (figure2) (19).

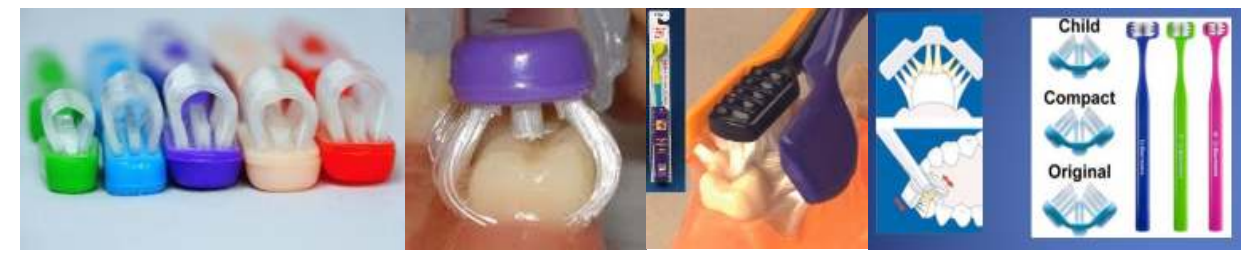

Figure 2. Three-sided toothbrushes

The method or technique of brushing teeth was taught by moving the brush back and forth with a light and steady movement on the surfaces of the teeth including when using a three-sided toothbrush that can brush three tooth surfaces at once. The tooth surfaces in question are biting surfaces or occlusal surfaces and buccal-lingual surfaces. If little children with GSA have not been able to brush their own teeth, parents can brush their teeth with the child sitting or lying in front of their parents with the child's head on their parent's lap. If the children have grown up, they and their parents stand with the position of the parents behind the children (figure 3).(20) Parents also sometimes complain that it is difficult to open their children's mouth. Extra effort is needed so that the children can open their mouth, such as being given a kind of booster to keep the mouth open (mouth opener) (figure 4). (21) The existence of this tool facilitates the process of checking and brushing teeth. In addition to the mouth opener available 
on the market, it can also be made from several wooden handles that resemble ice cream handles that are put together and wrapped in sterile gauze.

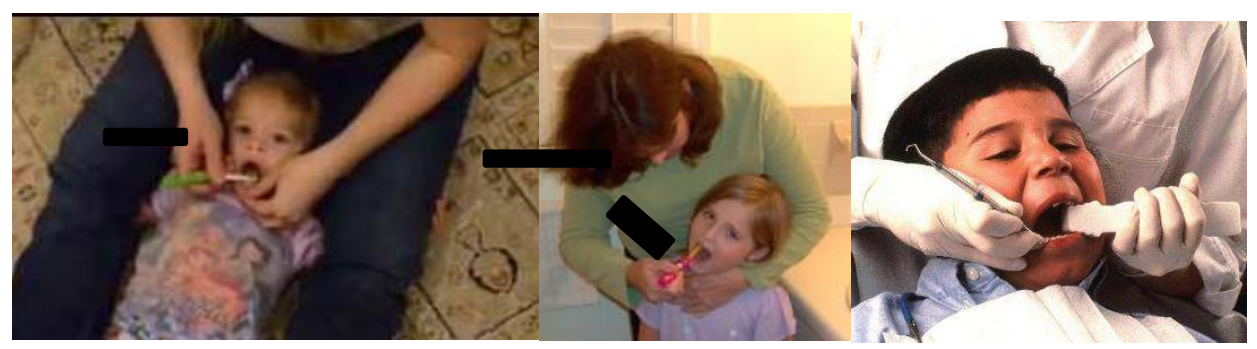

Figure 3. Position of brushing

Figure 4. Mouth children's teeth opener

As for the question of reducing vomiting reflexes, it is recommended to provide a gradual stimulus to children with GSA. Stimulus can be given by light oral massage around the lips until it continues to enter the mouth using a clean parent's finger and wrapped with sterile gauze or finger brush. The stimuli are then continued with toothbrushes without paste (Figures $5 \& 6$ ). (22) Children are also advised to gargle with warm water.

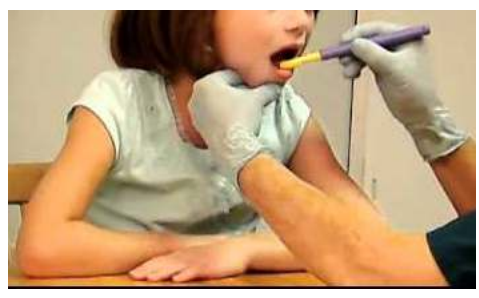

Figure 5. Oral massage

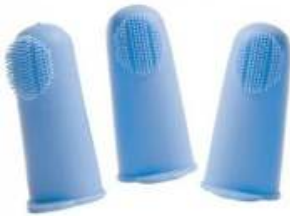

Figure 6. Finger tooth brush

Questions about prevention of cavities were answered with suggestions for parents and dentists. Parents are expected to be diligent in brushing their children's teeth properly and continue to train their children to independently brush their teeth. Considering that some children with GSA are able to understand visual better than audio, they can be given images of tooth brushing activities for children with GSA. Internet media provides many choices of images teaching tooth brushing to GSA children. Choices of series of images that shows the stages of tooth brushing starting from putting the paste on the brush to gargling are available, up to a more detailed selection of images such as the placement of a toothbrush in the mouth (pictures $7 \& 8)(23)(24)$. In addition, parents need to pay attention to the diet of children with GSA, especially to the types of sugar.

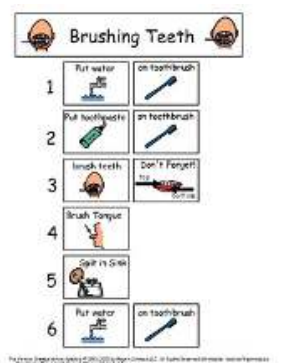

Figure 7. A series of

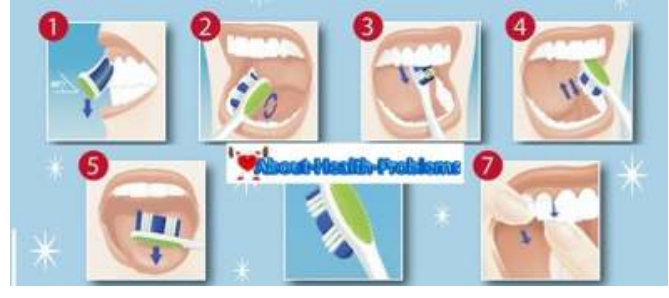

Figure 8. Order of tooth images brushing

The prevention by dentists includes pit and fissure sealant actions and topical fluoridation applications. Pit and fissure sealant action is a precautionary measure of cavities on the biting surfaces of the back teeth which has a deep recess. This action is carried out by providing dental coating material 
so that the biting surface recess is closed and becomes an easy-to-clean area (figure 9) (25). The action of topical fluoridation application is a precautionary measure of cavities, especially on the smooth surface of the teeth by administering the active substance of Fluoride. Fluoride application can be applied directly to the surface of the tooth using a small brush or using a special type of spoon. These fluoride preparations also vary in the forms such as liquid, gel or foam (figure 10) (26)(27).
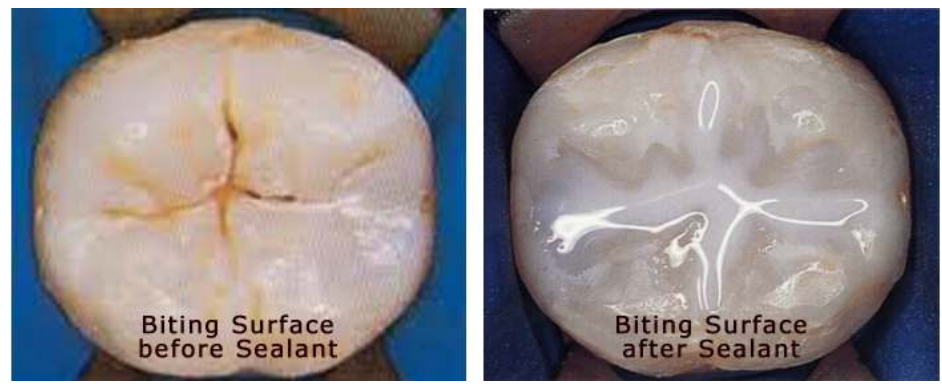

Figure 9. Biting surface of posterior tooth before and after sealant
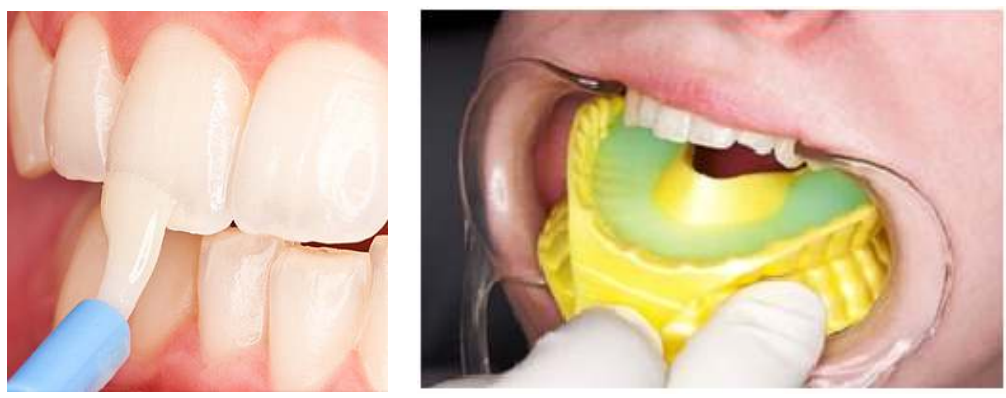

Figure 10. Application of Topical Fluoride

Toothpaste sold freely generally contains Fluoride as an ingredient for prevention of cavities. But the fluoride content in toothpaste is relatively small when compared to fluoride which is applied by dentists in dental care services. Despite in small concentrates, the use of toothpaste must be monitored so that it is not swallowed by children. Children who have not been able to gargle and throw it away are not advised to use toothpaste.

The next discussion was about taking children to the dentist. Parents are taught how to prepare children to visit a dentist. The keynote speaker explained the preparation needed to be done before and during the visit. Before the visit, images showing situations in the dental care services may be presented to the children. The images include medical personnel who use masks and gloves or images that show large lights that can turn on and off (figure 11) (17). In addition, before the visit, children also need to be trained to be able to accept the touch of the area around the head including the mouth. One of the journals also said that children with GSA who have been able to calm down on their haircut activities are more likely to be able to work together in dental care. (28) 


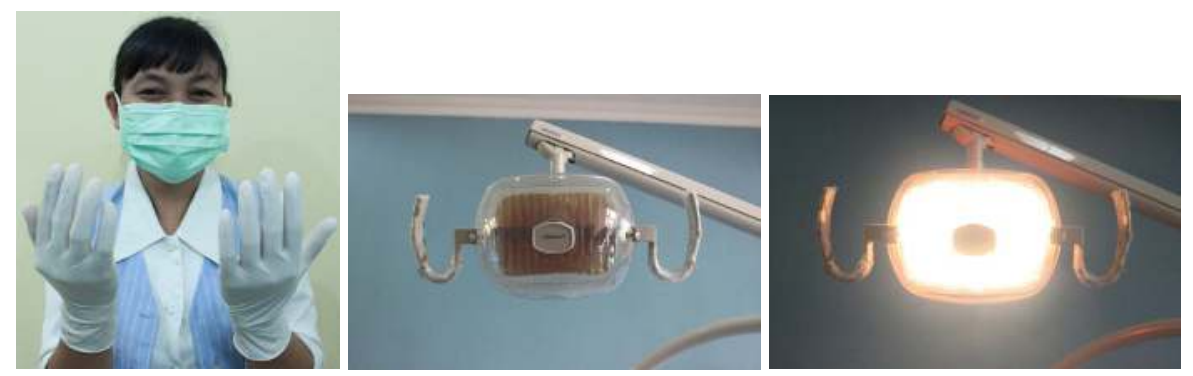

Figure 11. Medical personnel and a light at a dental care service

Before taking children with GSA to a dentist, parents should visit/contact the dentist in advance. Preparation of treating children with GSA also needs to be done by dentists and their teams. It is better for the children to go to the dentist not in a tired or emotional state and if necessary parents carry toys or tools that are they like and may calm them.

\section{CONCLUSION}

The conclusion of this activity is that there are still parents who have children with GSA who do not know how to treat their child's/family member's teeth. Parents' questions include brushing techniques, selection of brushes and pastes, prevention of cavities and the habit of swallowing paste or difficulty in brushing teeth due to vomiting reflexes. In addition, participants were also enthusiastic in preparing to take children with GSA to the dentist, which included not only preparing children with GSA, but prior notice was needed so that dentists and their team could prepare themselves.

\section{REFERENCES}

American Psychiatric Association. American Psychiatric Association. Diagnostic and Statistical Manual of Mental Disorders, Fourth Edition, Text Revision. Washington DC; 2000.

Kanner L. Autistic disturbances of affective contact. Nerv Child. 1943;2:217-50.

Murshid EZ. Oral health status, dental needs, habits and behavioral attitude towards dental treatment of a group of autistic children in Riyadh , Saudi Arabia. Saudi Dent J. 2005;17(3):132-9.

Hines E, Simonsen B. The Effects of Picture Icons on Behavior for a Young Student With Autism. Beyond Behav. 2008;Fall:9-18.

CP, Myers SM. Identification and evaluation of children with autism spectrum disorders. Pediatrics [Internet]. 2007 Nov [cited 2012 Jul 12];120(5):1183-215. Available from: http://www.ncbi.nlm.nih.gov/pubmed/17967920

Zinke K, Fries E, Kliegel M, Kirschbaum C, Dettenborn L. Children with high-functioning autism show a normal cortisol awakening response (CAR). Psychoneuroendocrinology [Internet]. Elsevier Ltd; 2010 Nov [cited 2012 Aug 21];35(10):1578-82. Available from: http://www.ncbi.nlm.nih.gov/pubmed/20409644

Autism Speaks. Autism Prevalence [Internet]. 2018. Available from: https://www.autismspeaks.org/what-autism/prevalence

Hadriani. Anak Autis Ada di Sekeliling Kita [Internet]. Tempo.co. 2013. Available from: http://www.tempo.co/read/news/2013/04/09/174472198/Anak-Autis-Ada-di-Sekeliling-Kita

Friedlander AH, Yagiela J a, Paterno VI, Mahler ME. The pathophysiology, medical management, and 
dental implications of autism. J Calif Dent Assoc [Internet]. 2003 Sep;31(9):681-91. Available from: http://www.ncbi.nlm.nih.gov/pubmed/14560872

M, Prathibha K. Management of a child with autism and severe bruxism: A case report. J Indian Soc Pedod Prev Dent [Internet]. Medknow Publications; 2008 Jun 1 [cited 2012 Sep 6];26(2):82. Available from: http://www.jisppd.com/article.asp?issn=09704388 ; year $=2008$; volume $=26$; issue $=2$; ppage $=82$; epage $=84$; aulast $=$

Loo CY, Graham RM, Hughes C V. Behaviour guidance in dental treatment of patients with autism spectrum disorder. Int J Paediatr Dent [Internet]. 2009 Nov [cited 2012 Sep 19];19(6):390-8. Available from: http://www.ncbi.nlm.nih.gov/pubmed/19619200

Kopycka-Kedzierawski DT, Auinger P. Dental needs and status of autistic children: results from the National Survey of Children's Health. Pediatr Dent [Internet]. 2008;30(1):54-8. Available from: http://www.ncbi.nlm.nih.gov/pubmed/18402100

Luscre DM, Center DB. Procedures for reducing dental fear in children with autism. J Autism Dev Disord [Internet]. $1996 \quad$ Oct;26(5):547-56. Available from: http://www.ncbi.nlm.nih.gov/pubmed/8906455

Pilebro C, Bäckman B. Teaching oral hygiene to children with autism. Int J Paediatr Dent [Internet]. 2005 Jan;15(1):1-9. Available from: http://www.ncbi.nlm.nih.gov/pubmed/15663439

Backman B, Pilebro C. Visual Pedagogy for Children with Autism. J Dent Child. 1999;(SreptemberOctober):325-31.

Fittipaldi-Wert J, Simpson R, Brock SJ. The use of visual supports for students with autism in inclusive physical education [Internet]. Vol. DAI-A 68/0. 2007. Available from: http://proquest.umi.com/pqdlink?did=1379567131\&Fmt=7\&clientI $\mathrm{d}=79356 \& \mathrm{RQT}=309 \& \mathrm{VName}=\mathrm{PQD}$

Wibisono WL, Suharsini M, Wiguna T, Sudiroatmodjo B, Budiardjo SB, Auerkari EI. Perception of dental visit pictures in children with autism spectrum disorder and their caretakers: A qualitative study. J Int Soc Prev Community Dent. 2016;6(4):359-65.

Mc Donald R, Avery D. Dentistry for the child and adolescent. 6th ed. St. Louis: Mosby; 1994. 605, $611 \mathrm{p}$.

Collis curve toothbrush [Internet]. 2017 [cited 1BC Aug 27]. Available from: https://colliscurve.com/

Dental care news. How You're Wrecking Your Kids' Milk Teeth [Internet]. [cited 1BC Aug 27]. Available from: https://www.dentalcarenews.co.uk/developments/media/how-youre-wreckingyour-kids-milk-teeth/

Search M. Open Wide [Internet]. [cited 1BC Aug 27]. Available from: https://www.medicalsearch.com.au/reusable-mouth-prop-open-wide/p/118408

Autism Resources. Gum Finger Massager [Internet]. 2018. Available from: https://www.nationalautismresources.com/finger-gum-massager-set-of-3

Problems AH. Children Dental Problems [Internet]. Available from: http://about-healthproblems.com/children-dental-problems/

Pay T. Hygiene Visuals: Schedules and Visual Instructions for Kids with Autism [Internet]. 2018. Available from: https://www.teacherspayteachers.com/Product/Hygiene-Visuals-Schedules- 
and-Visual-Instructions-for-Kids-with-Autism-307226

Andow K. Sealants [Internet]. 2018. Available from: https://www.andowdental.com/

Care ED. Fluoride Application [Internet]. 2018. Available from: http://www.empiredentalcare.net/fluoride.html

Family BD. A Topical Fluoride Treatment Could Protect Your Child from Tooth Decay [Internet]. 2018. Available from: http://www.bohledental.com/blog/post/a-topical-fluoride-treatmentcould-protect-your-child-from-tooth-decay.html

Marshall J, Sheller B, Williams BJ, Mancl L, Cowan C. Cooperation predictors for dental patients with autism. Pediatr Dent [Internet]. 29(5):369-76. Available from: http://www.ncbi.nlm.nih.gov/pubmed/18027770 